\title{
Strategy-oriented web-based English instruction - A meta-analysis
}

\author{
Mei-Mei Chang \\ National Pingtung University of Science and Technology, Taiwan \\ Mei-Chen Lin \\ National Pingtung University of Science and Technology, Taiwan
}

\begin{abstract}
In this meta-analysis study, a total of thirty-one studies related to strategy use of students in Taiwan in a web-based English context were identified, collected, and analysed. Three criteria for selecting the appropriate studies are (a) they must have applied web-based instruction; (b) they must be related to English learning; and (c) they had to provide one of the following data in order to calculate effect size (ES), including means and standard deviation (SD), $F$ values, or $t$ values. The characteristics were divided into three groups; that is, study characteristics, methodological characteristics, and design characteristics. The findings reveal that predicting, summarizing, self-questioning and clarifying; text annotation with pictures, and glossing were strategies with higher effect size $(\mathrm{ES}>0.920)$. Findings from the meta-analysis in this study could provide a basis for designing and developing a strategy-oriented web-based instruction.
\end{abstract}

\section{Introduction}

Research in computer-assisted language learning (CALL) has revealed that students were motivated and liked working with the computer-based courseware (Chang \& Lehman, 2002). Learners became selfdirected, active and exploratory in a very short time when learning from a multimedia program. Internet technology has revolutionized traditional CALL and has become a popular distribution channel for information. As a consequence, web-based learning continues to increase (Chang 2007).

In institution-wide university language programs, the use of Internet technology has been associated with increased resources. It provides flexibility, interactivity, and autonomy for learners who may use the target language for different purposes in which learners' individualized needs and self-paced learning are stressed. Web-based instruction is theoretically a suitable environment for students to take charge of their own learning (Chen, 2002; Lamy \& Goodfellow, 1999; Lee, 2002; L. Lee, 2005; Papert, 1996). However, research indicates that attrition rates can be a problem associated with learning in cyberspace (Carr, 2000; Edwards \& Chang, 2001). Online learners' motivation may decline easily when the materials fail to attract their attention, when they get lost in the instruction, or when they fail to follow the schedule (Chang, 2002). Thus, strategies that encourage students to develop self-regulation must be implemented in order to increase the retention rate and success of online learning.

Studies show that the use of strategies help students develop the ability to become aware of their own knowledge construction process, and the opportunity to reflect on present assumptions, premises, beliefs, or conceptualizations, which facilitates cognitive growth and leads to better learning achievement (Chang, 2005). In learning, students have to use a variety of strategies to accomplish academic tasks. Language learning strategies encourage greater overall self-direction for learners and help learners to develop communicative competence. However, researchers have claimed that the strategies need to be clearly introduced to learners; strategy instruction should be direct and explicit, giving conditional metacognitive knowledge about when and how to use a strategy (Paris, Cross, \& Lipson, 1984; Pressley, Snyder, \& Cariglia-Bull, 1987). The process of internalizing strategy use should be supported by instructional aids such as modelling, guided practice, offering various opportunities for practice, and co-operation among students (Pressley, Goodchild, Fleet, Zajchowski, \& Evans, 1989).

To date, most of the studies have designed their instructional strategies based on traditional narrative review (Liao, 2007). Narrative review is largely subjective and also difficult when there are more than a few studies involved. Meta-analysis, in contrast, applies objective formulas and can be used with numbers of studies. In order to obtain more accurate results, a meta-analysis was conducted. The studies, related to strategy use of college students in web-based language context, were identified, selected, and analysed. 
The purpose of this study was to find the most effective strategy use of students in Taiwan in a web-based English context. This strategy can then be applied in an English web-based course to examine its influence on subjects, and its effectiveness can be verified or challenged based on the results of the experimental study.

\section{Literature Review}

\section{Research on online reading strategies}

Anderson (2003) adapted the Survey of Reading Strategies (SORS) (Sheorey \& Mokhtari, 2001) to investigate 247 online learners' reading strategies. The adapted Online SORS (OSORS) consists of 38 items that measure metacognitive reading strategies, including 18 global reading strategies, 11 problem solving strategies, and nine support strategies. The Crobach's alpha for the overall OSORS was .92. The reliabilities for global reading strategies was .77; for problem solving strategies it was .64; and for support strategies it was .69. The findings revealed that eight of the top 12 strategies students used were problem solving strategies, while the 12 lowest ranked strategies were support reading strategies (Mokhtari \& Reichard, 2002).

Chang and $\mathrm{Wu}(2003)$ also investigated students' strategy use in a web-based learning environment. The Motivated Strategies for Learning Questionnaire (MSLQ) (Pintrich, Smith, Garcia, \& McKeachie, 1991) modified by the researcher was used in this study to investigate learners' motivation perception and strategy uses. The results of the study show that the top five strategies students used belong to metacognitive self-regulation strategies. Huang (2006a) studied Taiwanese college students' strategy use when reading four articles online. It was found that students used support strategies the most often, followed by global strategies for both easy articles and difficult articles. In another study, Huang (2006b) examined EFL learners' online reading strategies and the effects of strategy use on comprehension, and evaluated a web-based reading program. The results showed that among the 15 strategies used in this study, support strategies made up the overwhelming proportion of strategy use while problem-solving strategies were used the least.

\section{Studies on the role of strategy instruction}

Research conducted to investigate learners' reading strategies has indicated that contextual guessing is a successful strategy for English as a Foreign Language readers (Hosenfeld, 1984). When comparing the difference of strategy use between different language users, results of the studies show that students with different language backgrounds use similar strategies (Block, 1986; Sheorey \& Mokhtari, 2001). In addition, students with different language abilities use different strategies when learning (Block, 1992).

Shen's (2003) study found that more proficient learners used a wide variety of strategies to solve problems while less proficient learners chose to skip unknown words. Chang $(2004 ; 2005)$ explored online learners' strategy use and individual difference. The results show that students have affirmative performance on strategy utilization. Students' self-expectancy and their strategy use are related positively. Active learners applied self-regulation strategies more frequently than passive learners (Chang, 2005).

However, based on the results of Cheng's study (2009), no significant differences among high-, mid-, and low-achievers in their overall and specific types of strategy use were found while significant proficiency effects were detected in the use of individual strategies; compared to less proficient learners, more proficient learners were found to employ more read-aloud, skimming, guessing from the context, and analysing sentence patterns and grammar structures strategies.

Other studies proved the effectiveness and positive influence of strategy instruction on students' performances based on the quantitative and qualitative data. The findings of Huang's study (2010) suggested that after the strategy instruction, most students improved their reading comprehension, and their attitudes toward reading became more positive. In addition, after reading strategy instruction, the students felt more confident and became more interested in reading English, and more importantly, their English reading comprehension had also been improved. According to Yeh (2006), students with reading strategy instruction significantly outperformed those without it. Results of the questionnaire administered on those in the experimental group also showed their positive responses toward the strategies instruction. 
Numbers of studies have claimed the power of strategy application. However, students need some guides and instructions to internalize strategy use. Learners need to learn how to use effective strategies to achieve their desired goals. Nunan $(1996,1997)$ provides a good rationale for integrating explicit instruction of language learning strategies into classroom curriculum. He suggested that language classes should not only teach language content but also develop learning processes as well (Nunan, 1996). A strategy-oriented instruction is therefore needed.

\section{Meta-analysis on computer-assisted instruction}

Starting from the 1970s, a number of studies on the effectiveness of computer-assisted instruction (CAI) on learners' achievement have been published. Kulik and his colleagues published a series of metaanalysis regarding the effects of computers on learning starting from the 1980s (e.g., Kulik \& Kulik, 1986; Kulik, Kulik, \& Schwalb, 1986; Kulik, Kulik, \& Bangert-Drowns, 1985; Kulik, Kulik, \& Cohen, 1980). Since 1990, more meta-analyses related to the effectiveness of computers were released and their results reported positive outcomes for students with CAI experiences (Blok, Oostdam, Otter, \& Overmaat, 2002; Christman, Badgett, \& Lucking, 1997; Soe, Koki, \& Chang, 2000). Although research results seem to support the application of CAI in instruction, diverse viewpoints on this issue were proposed (e.g., Clark, 1983). None of the above-mentioned studies, however, are conducted in Taiwan. Among the few studies, Liao (2007) conducted a meta-analysis to synthesize existing research comparing the effects of CAI versus traditional instruction (TI) on students' achievement in Taiwan. The results from this study also favour the CAI groups.

The focus of the previous meta-analyses is on the effects of CAI on students' learning. Many of them have found positive outcomes for students with CAI experiences. However, none of them have investigated the strategy use of students in a web-based context, particularly in Taiwan. Therefore, this study aims to provide the first meta-analysis of strategy use of students in Taiwan in a web-based English context.

\section{Methodology}

Meta-analysis refers to the statistical analyses that are used to synthesize summary data from a series of studies (Jain, 2011). The present statistical analysis follows the meta-analysis research steps modified from Cooper's approach (2010):

1. Finding and selecting studies:

- Collect relevant research

- Build criteria to choose research

- Select the appropriate research

2. Identifying and coding study characteristics

- $\quad$ Design coding form (as shown in Table 1)

- Code data

3. Analysing the studies selected

- Effect size measure: Effect size was defined as the difference between the mean scores of two groups divided by the SD of the control group (Liao, 2007). $F$ values or $t$ values were applied to calculate the ES for those studies without means and SD. The formulas used to measure effect size are shown in Table 2.

- Dealing with relationships between variables, such as correlations.

4. Reporting meta-analytic findings 
Table 1

The studied variables in each characteristic

\begin{tabular}{|c|c|}
\hline Characteristics & Variables \\
\hline \multirow[t]{3}{*}{ Study Characteristics } & Grade level \\
\hline & Type of publication \\
\hline & Year of publication \\
\hline \multirow[t]{5}{*}{ Methodological characteristics } & Instructor bias \\
\hline & Instrumentation \\
\hline & Sample size \\
\hline & Statistical power \\
\hline & Type of research design \\
\hline \multirow[t]{6}{*}{ Design characteristics } & Comparison group \\
\hline & Duration of treatment \\
\hline & Implementation of innovation \\
\hline & Type of instruction for treatment \\
\hline & Type of CALL \\
\hline & Type of strategies \\
\hline
\end{tabular}

Table 2

Formulas for calculating effect size

\begin{tabular}{ll}
\hline Statistics types & Formulas \\
\hline Mean and standard deviation & $\mathrm{ES}=\left(M_{\mathrm{x}}-M_{\mathrm{c}}\right) / \mathrm{SD}_{\mathrm{c}}$ \\
$t$ Value & $\mathrm{ES}=t \times \sqrt{1 / N x+1 / N c}$ \\
$F$ Value & $\mathrm{ES}=\sqrt{F} \times \sqrt{1 / N x+1 / N c}$
\end{tabular}

Note. $\mathrm{ES}=$ effects size; $\mathrm{M}_{\mathrm{x}}=$ experimental group; $\mathrm{M}_{\mathrm{c}}=$ control group; $\mathrm{SD}_{\mathrm{c}}=$ deviation of the control group; $\mathrm{Nx}=$ number of subjects in the experimental group; $\mathrm{Nc}=$ number of subjects in the control group.

\section{Results}

Table 3 reports the number of comparisons and the study weight ESs (defined as the overall one ES for a single study). The total number of subjects across 31 studies was 3,414. Among the 31 studies included in the present synthesis, 29 (94\%) of the study-weighted ESs were positive and favoured the CALL group, while $2(6 \%)$ of them were negative and favoured the traditional instruction group. The study-weighted ESs ranged from -0.1956 to 2.8187 . The overall grand mean for all 31 study-weighted ESs was 0.6732 while the overall grand median for all 31 study-weighted ESs was 0.6581 . The SD of 0.6790 reflects the great variability of ESs across studies. 
Australasian Journal of Educational Technology, 2013, 29(2).

Table 3

Number of comparisons and study-weighted effect sizes for studies $(n=31)$

\begin{tabular}{|c|c|c|}
\hline Author(s) (Year) & $\begin{array}{c}\text { No. of } \\
\text { Comparisons }\end{array}$ & ES \\
\hline Chen (2007) & 1 & 2.8187 \\
\hline Chan \& Liou (2005) & 1 & 2.7423 \\
\hline Chou (2009) & 1 & 1.4153 \\
\hline Lin (2006) & 1 & 1.3690 \\
\hline Tsou, Wang \& Li (2002) & 1 & 1.2531 \\
\hline Wang (2007) & 3 & 1.1365 \\
\hline Huang (2003) & 1 & 1.0675 \\
\hline Chang \& Lehman (2002) & 1 & 0.8864 \\
\hline Chang (2007) & 1 & 0.7978 \\
\hline Deng (2009) & 1 & 0.6699 \\
\hline Liou, Wang \& Yeh (1992) & 1 & 0.6581 \\
\hline Wang (2006) & 1 & 0.6573 \\
\hline Chang \& Ho (2009) & 1 & 0.6430 \\
\hline $\mathrm{Lu}(2008)$ & 1 & 0.5756 \\
\hline Chen (2006) & 1 & 0.5200 \\
\hline Chou (2006) & 1 & 0.5110 \\
\hline Liu, Chen \& Chang (2010) & 1 & 0.4847 \\
\hline Huang (2009) & 1 & 0.3653 \\
\hline Chang, Chang, Su \& Chen (2007) & 1 & 0.3649 \\
\hline Lin $(2007)$ & 1 & 0.3570 \\
\hline M. L. Lee, (2005) & 4 & 0.3390 \\
\hline Shiu (2002) & 1 & 0.3246 \\
\hline Chang (2008) & 1 & 0.3058 \\
\hline Peng \& Hsu (2006) & 1 & 0.2673 \\
\hline Tsou, Wang \& Tzeng (2006) & 3 & 0.2669 \\
\hline $\mathrm{Su}(2003)$ & 1 & 0.1481 \\
\hline Li (2009) & 1 & 0.1108 \\
\hline Chiang (2009) & 1 & 0.1025 \\
\hline Wang (2003) & 2 & 0.0108 \\
\hline Kang (2007) & 1 & -0.1041 \\
\hline Lan, Sung \& Chang (2009) & 1 & -0.1956 \\
\hline Over all grand mean & & 0.6732 \\
\hline Over all grand median & & 0.6581 \\
\hline Overall grand SD & & 0.6790 \\
\hline Overall grand Max & & 2.8187 \\
\hline Overall grand Min & & -0.1956 \\
\hline
\end{tabular}


The results of this meta-analysis indicated that CALL has significantly positive effects on students' achievement over TI. According to Cohen (1977), an effect is considered medium when ES $=0.5$ and large when $\mathrm{ES}=0.8$. The effectiveness of CALL is also confirmed by $94 \%$ of positive study-weighted ES values. With 3,414 subjects included in this meta-analysis, the generalization of this study is considered stable.

Table 4 reports the means and standard deviations of study-weighted ESs for coded variables. Some trends based on the analysis of these variables will be discussed in the following section.

Table 4

Means and standard deviations of study-weighted ESs for coded variables

\begin{tabular}{lcccc}
\hline Variables & $N$ & $\%$ & ES & SD \\
\hline $\begin{array}{l}\text { Study characteristics } \\
\text { Grade level }\end{array}$ & & & & \\
$\quad$ 1st-6th & 7 & 22.58 & 0.609 & 0.413 \\
7th-9th & 2 & 6.45 & 0.200 & 1.654 \\
10th-12th & 3 & 9.68 & 1.329 & 1.292 \\
College & 18 & 58.07 & 0.851 & 0.570 \\
Graduate & 1 & 3.22 & 0.677 & 0.000 \\
Type of publication & & & & \\
$\quad$ Journal article & 13 & 41.94 & 0.598 & 0.689 \\
Dissertation/thesis & 18 & 58.06 & 0.728 & 0.715 \\
Year of publication & & & & \\
1991-1995 & 1 & 3.22 & 0.658 & 0.823 \\
2001-2005 & 9 & 29.04 & 0.782 & 0.897 \\
2006-2010 & 21 & 67.74 & 0.627 & 0.717
\end{tabular}

Methodological characteristics

$\underline{\text { Instructor bias }}$

$\begin{array}{lcccc}\text { Same } & 20 & 64.52 & 0.770 & 0.567 \\ \text { Different } & 5 & 16.13 & 0.729 & 0.123 \\ \text { Unspecified } & 6 & 19.35 & 0.962 & 1.275 \\ \text { Instrumentation } & & & & \\ \text { Local } & 28 & 90.32 & 0.737 & 0.622 \\ \text { Standardized } & 2 & 6.45 & 1.138 & 1.157 \\ \text { Mixed } & 1 & 3.23 & 1.152 & 0.000 \\ \text { Sample size } & & & & \\ 1-50 & 12 & 38.71 & 0.828 & 0.894 \\ 51-100 & 6 & 19.35 & 0.583 & 0.442 \\ 101-300 & 13 & 41.94 & 0.861 & 0.599\end{array}$


Table 4 (continued)

\begin{tabular}{lcccc}
\hline Variables & $N$ & $\%$ & ES & SD \\
\hline Statistical power $(\mathrm{N}>15)$ & & & & \\
\hline$\quad \begin{array}{l}\text { Adequately minimized } \\
\text { Probably threat }\end{array}$ & 28 & 90.32 & 0.847 & 0.639 \\
$\begin{array}{l}\text { Type of research design } \\
\text { One group repeated measure }\end{array}$ & 3 & 9.68 & 0.313 & 1.125 \\
$\quad$ Pretest-posttest control group & 5 & 16.13 & 1.376 & 0.964 \\
$\quad$ Nonequivalent control group & 5 & 16.13 & 1.122 & 0.998 \\
The posttest-only control-group design & 18 & 58.06 & 0.564 & 0.456 \\
\end{tabular}

Design characteristics

Comparison group

Traditional instruction

No comparison group

Web-based instruction

Others

Duration of treatment

Less than 1 week

2-10 week

11-25 week

Unspecified

Implementation of innovation

Replacement for usual instruction

Supplement to instruction

Type of instruction for treatment

Large group

Small group

Type of CAI

Traditional CALL

Multimedia

Computer Mediated Communication (CMC)

Web-based Instruction

Type of strategies

With Strategy

Unspecified

$\begin{array}{llll}17 & 54.84 & 0.546 & 0.461 \\ 5 & 16.13 & 1.226 & 0.914 \\ 4 & 12.90 & 0.691 & 0.406 \\ 5 & 16.13 & 1.416 & 0.924\end{array}$

$\begin{array}{cccc}2 & 6.45 & 1.195 & 0.252 \\ 17 & 54.84 & 1.158 & 0.370 \\ 10 & 32.26 & 0.614 & 0.656 \\ 2 & 6.45 & 1.631 & 1.023\end{array}$

$\begin{array}{llll}20 & 64.52 & 0.774 & 0.710\end{array}$

$\begin{array}{llll}11 & 35.48 & 0.848 & 0.720\end{array}$

$\begin{array}{cccc}30 & 96.78 & 0.854 & 0.620 \\ 1 & 3.22 & -0.970 & 0.000\end{array}$

$\begin{array}{cccc}4 & 12.90 & 0.930 & 0.248 \\ 10 & 32.26 & 0.587 & 0.684 \\ 4 & 12.90 & 0.994 & 1.230 \\ 13 & 41.94 & 0.871 & 0.618\end{array}$

$\begin{array}{llll}26 & 83.87 & 0.559 & 0.660 \\ 5 & 16.13 & 1.268 & 0.784\end{array}$




\section{Discussion}

The following section discusses some trends based on the analysis of studied variables in the accumulated research base, as shown in Table 4 .

\section{Study characteristics}

For the grade level variable, there was no significant difference of mean ES. The smallness of the ES associated with junior high school (7th-9th graders) may be due to the fact that students in this grade level in Taiwan have to study very hard for a nationwide senior-high-school entrance examination and applying CALL may not be a sensible approach for this purpose. The highest ES falls on the 10th to 12th graders, students in senior high schools or vocational schools. This might be due to the fact that those students have more class choices. Teachers, as a result, have more opportunities to implement different instructional approaches in their classes.

According to Christman et al. (1997) and Glass, McGaw, and Smith (1981), in meta-analysis, source of studies is always an important factor to be examined. Approximately $42 \%$ of studies were from journal articles, while $58 \%$ were from dissertations or theses. With the rapid advance in technology, the CALL has been more commonly applied in the educational field. More dissertations or theses related to CALL, as a result, have been conducted. The result, however, challenges what Glass et al. (1981, p. 277) proposed; that is, the larger ES associated with published articles is typical in the meta-analysis.

The variable, the year of publication, in meta-analysis allows an assessment of the effect of CALL over time. About $97 \%$ of studies located were published after 2001, suggesting that CALL studies have just become more popular over the last ten years around the world. It is expected, therefore, that more studies will be published. The result shows that CALL studies published between 2001 and 2005 have the highest mean ES (0.782), which might be explained by the novelty effects of technology. Clark (1985, p.3) has pointed out that the positive effect of computer-based instruction (CBI) over other instructional strategies "...was the uncontrolled but systematic influence of different instructional methods, curriculum content and/or novelty." The result that shows lower ESs for more recent studies indicates a novelty effect can be evidence to support Clark's point.

\section{Methodological characteristics}

Clark (1985) claimed that when the CBI and the traditional treatments were designed by the same instructor, the college CBI would be reduced to insignificant levels. The findings of the present synthesis seem to support Clark's point. Although the studies with the same instructors had slightly higher ES than studies with different instructors, the differences in ES were insignificant.

For instrumentation, more than $90 \%$ of instruments used in the studies were developed by researchers, while less than $10 \%$ of studies applied standardized instruments. Possible explanations are that CALL is a new field in educational research, and only a few instruments have been published and made available. In addition, the higher mean ES associated with studies using standardized instruments suggests that it is necessary to develop more standardized instruments for evaluating the effects of CALL.

The sample size of a study may have a significant influence on the statistical power of the study. In general, if the sample size gets larger, the statistical power gets better, which is proved by the present meta-analysis. The largest mean ES was associated with studies with the largest sample size (101-300).

As to statistical power, the mean ES of studies coded as adequately minimized was significantly higher than the mean ES of studies coded as probably threat. In general, when the subjects are less than 15 at each comparison group in an experimental study, the result is generally considered less reliable. The result of the present synthesis, therefore, supports this point.

Among the different types of research design, the higher mean ES was associated with studies using repeated measure. According to Liao (2007), although this type of design is usually believed to be methodologically weaker than other types of designs, in some cases like the ones in the present study, repeated measure design are stronger than other designs. 


\section{Design characteristics}

For the comparison group, the type coded as "Others" had the highest mean ES although only slightly higher than that of no comparison group. This result suggests that CALL becomes more effective when more innovative types of comparison groups are applied, or when there is no instruction for the comparison group. According to the results, CALL is more effective than TI on students' achievement.

In meta-analysis, duration of treatment is usually a critical variable. At the present synthesis, the highest ES was associated with studies with unspecified duration of treatment. Since only two studies were coded as unspecified, the results should not be over-generalized. However, it is noticeable that the lowest mean ES of the longest duration of treatment supports the point that the effects of new media to instruction were because of a novelty effect, and the ES was reduced when treatment lasted for a longer period of time (Clark, 1983).

Whether to use a new innovation as a replacement or usual instruction or as a supplement to instruction is usually a difficult decision for teachers. In general, the decision is made based on which approach can provide more effective outcomes. The trivial difference of mean ES between studies coded as replacement and supplement indicated that whether CALL was used as a replacement for conventional instruction or as a supplement to instruction had the same effect on students' achievement.

Among the 31 studies, 30 (97\%) employed large group instruction for the CALL classes, while only 1 $(3 \%)$ was for small group instruction. The significantly higher mean ES of studies with large groups suggest that CALL is more effective when implemented in large group settings.

Four types of CALL were coded for the 31 studies included. Among them, $13(42 \%), 10(32 \%)$ and 4 $(13 \%)$ studies were coded as web-based instruction, multimedia and traditional CALL, respectively. Only $4(13 \%)$ studies were coded as computer mediated communication (CMC), which was associated with the highest ES. Since only four studies were coded, the results may be considered tentative.

For type of strategies, three strategies had the highest mean ESs, and they were (1) reciprocal teaching (predicting, summarizing, self-questioning and clarifying) (ES = 1.1137), (2) marginal glosses-multiple choice glossing with feedback $(\mathrm{ES}=0.955)$, and $(3)$ text annotation with picture $(\mathrm{ES}=0.930)$. According to Cohen (1977), an effect is considered medium when $\mathrm{ES}=0.5$ and large when $\mathrm{ES}=0.8$. The results of the present synthesis indicate that these three strategies are the most effective.

\section{Conclusion}

Web-based instruction is theoretically a suitable environment for students to take charge of their own learning. In learning, students have to use a variety of strategies to accomplish classroom academic tasks. Language learning strategies encourage greater overall self-direction for learners and help learners develop communicative competence. Findings from the meta-analysis in this study could provide a basis for designing and developing a strategy-oriented web-based instruction. Then, an experiment could be conducted to examine the effect of the strategy-oriented web-based English instruction. It is hoped that the strategy-oriented web-based English instruction is able to benefit online learners and to increase their success of online learning.

\section{Acknowledgements}

This study was conducted as part of a research project funded by the National Science Council, Taiwan. Project Number: 98-2410-H-020-004-MY2. The authors would like to give special thanks to the reviewers and the editor of AJET for their insightful comments on the draft of this article. 


\section{References}

References marked with an asterisk indicate studies included in the meta-analysis.

Anderson, N. J. (2003). Scrolling, clicking, and reading English: Online reading strategies in a second/foreign language. The Reading Matrix, 3(3), 1-33.

Block, E., (1986). The comprehension strategies of second language readers. TESOL Quarterly, 20, 163 194.

Block, E., (1992). See how they read: Comprehension monitoring of L1 and L2 readers. TESOL Quarterly, 26, 319-342.

Blok, H., Oostdam, R., Otter, M., \& Overmaaat, M. (2002). Computer-assisted instruction in support of beginning reading instruction: a review. Review of Educational Research, 72(1), 101-130.

Carr, S. (2000). As distance education comes of age, the challenge is keeping the students. Chronicle of Higher Education, 46, 39-41.

*Chan, T. \& Liou, H. (2005). Effects of web-based concordancing instruction on EFL students' learning of verb-noun collocations. Computer Assisted Language Learning. 18(3), 231-250.

Chang, M. M. (2002). The role of intrinsic motivation on English learning. Bulletin of National Pingtung University of Science and Technology, 11(2), 154-159.

Chang, M. M. (2004). Effects of the relevance component on EFL learners: Acomparison between English majors and non-English majors. Studies in English Language and Literature, 13, 99-106.

Chang, M. M. (2005). EFL online learner's self-efficacy and self-regulation: A study with active learners and passive learners. Studies in English Language and Literature, 15, 13-20. NSC: 91-2411-H-020001 .

*Chang, M. M. (2007). Enhancing web-based language learning through self-monitoring. Journal of Computer Assisted Learning, 23, 197-196.

*Chang, M. M., \& Ho, C. M. (2009). Effect of locus of control and learner-control on web-based language learning. Computer Assisted Language Learning, 22(3), 189-206.

*Chang, M. M., \& Lehman, J. D. (2002). Learning foreign language through an interactive multimedia program: An experimental study on the effects of the relevance component of the ARCS model. CALICO journal, 20(1), 81-98.

Chang, M. M., \& Wu, Y. M. (2003). EFL learners' self-efficacy and learning strategies uses in a webbased environment. Proceedings of 2003 International Conference on English Teaching and Learning in the Republic of China. 117-126. NSC: 91-2411-H-020-001.

*Chang, S. C. (2008). The effects of computer-assisted multimedia English pop song instruction on elementary school students' motivation and achievements in their English acquisition (Unpublished master's thesis). National Kaohsiung Normal University, Kaohsiung, Taiwan

Chang, T. C., Chang, C. L., Su. Y. L., \& Chen, F.S. (2007) Enhancing the English learning effectiveness of the $8^{\text {th }}$ grade students using an online interactive English system. World Transactions on Engineering and Technology Education, 6(1), 53-48.

Chen, C. S. (2002). Self-regulated learning strategies and achievement in an introduction to information system course. Information Technology, Learning and Performance Journal, 20(1), 11-25. 
*Chen, F. (2007).The effects of voiced-based synchronous and asynchronous CMC on EFL learners' oral proficiency (Unpublished master's thesis). National Taiwan Normal University, Taipei, Taiwan.

*Chen, Y. H. (2006). The effects of multimedia aids on EFL students' reading comprehension (Unpublished master's thesis). Yuan Ze University, Chung-Li, Taiwan.

Cheng, M. F. (2009). Effects of English proficiency and gender differences on reading strategy use. (Unpublished master's thesis). National Pingtung Institute of Commerce, Pingtung, Taiwan.

*Chiang, Y. C. (2009). A study of the diffusion of English podcasting learning and its impact on seventh graders' achievement and motivation (Unpublished master's thesis). National Chiayi University, Chiayi, Taiwan.

*Chou, C. Y. (2006). The effects of cooperative evaluation and group rewards with writing \& valuationcooperative online learning (WE-COOL) system on senior high school students' English writing achievement and attitudes (Unpublished master's thesis). National Chiayi University, Chiayi, Taiwan.

*Chou, H. C. (2009). Effects of weblog-based instruction on English writing performance of vocational high school students (Unpublished master's thesis). National Kaohsiung Normal University, Kaohsiung, Taiwan.

Christman, E., Badgett, J., \& Lucking, R. (1997). Progressive comparison of the effects of computerassisted instruction on the academic achievement of secondary students. Journal of Research on Computing in Education, 29(4), 325-337.

Clark, R. E. (1983). Reconsidering research on learning from media. Review of Educational Research, 53(4), 445-449.

Clark, R. E. (1985). Computer research confounding. Paper presented at the annual meeting of the American Educational Research Association, Chicago, IL (ERIC Document Reproduction Service No. ED 263876).

Cohen, J. (1977). Statistical power analysis for the behavioral sciences (Rev. ed.). New York: Academic Press.

Cooper, H. M. (2010). Research synthesis and meta-analysis: A step-by-step approach (4th ed.). Los Angeles, CA: Sage.

*Deng, P. Y. (2009). The effects of reading strategy instruction integrated with English electronic storybooks on Chinese EFL sixth graders' reading comprehension (Unpublished master's thesis). National Changhwa Normal University, Changhwa, Taiwan.

Edwards, G., \& Chang, M. M. (2001, June). Guiding students to success in online learning - the buck starts here. Paper presented at the annual meeting of Topics on Distance Learning, Calumet, Hammond, IN.

Glass, G. V., McGaw, B., \& Smith, M. L. (1981). Meta-analysis in social research. Beverly Hills, CA: Sage Publications.

Hosenfeld, C. (1984). Case study of ninth grade readers. In C. Anderson \& A. H. Urquhart, (Eds.), Reading in a Foreign Language (pp. 231-224). London: Longman.

*Huang, P. C. (2003). A study of the effect on applying web-based teaching to freshman's English outside reading (Unpublished master's thesis). Tzu Chi University, Hualien County, Taiwan.

Huang, S. C. (2006a). A study of English learning strategy of technology college students in southern Taiwan (Unpublished master's thesis). Leader University, Tainan, Taiwan. 
Huang, S. C. (2006b). EFL learners' online reading strategy use and text comprehension: An exploratory study (Unpublished doctoral dissertation). National Taiwan Normal University, Taipei, Taiwan.

Huang, Y. C. (2009). The effect of game-assisted English sentence patterns learning on elementary students' learning achievement (Unpublished master's thesis). National Taiwan Normal University, Taipei, Taiwan.

Huang, Z. H. (2010). The effects of reading strategy instruction on EFL students' reading comprehension. National Yunlin University of Science and Technology, Yunlin, Taiwan.

Jain, V. (2011). A modular approach of reporting meta analysis statistics using forest plots. Proceedings of PharmaSUG 2011 Conference, Chicago, USA, 1-8.

*Kang, H. K. (2007). A study of the effectiveness of WebQuest on different ability junior high students' English learning achievement and attitudes (Unpublished master's thesis). Fo Guang University, Yilan.

Kulik, C. L., \& Kulik, J. (1986). Effectiveness of computer-based education in colleges. AEDS Journal, 19(2-3), 81-108.

Kulik, C. L., Kulik, J., \& Schwalb, B. (1986). Effectiveness of computer-basesd adult education: a metaanalysis. Journal of Educational Computing Research, 2(2), 235-252.

Kulik, J., Kulik, C. L., \& Bangert-Drowns, R. L. (1985). Effectiveness of computer-based education in elementary pupils. Computer in Human Behaviors, 1, 59-74.

Kulik, J., Kulik, C. L., \& Cohen, P. (1980). Effectiveness of computer-based college teaching: a metaanalysis of findings. Review of Educational Research, 50, 525-544.

Lamy, M. N., \& Goodfellow, R. (1999). Reflective conversation in the virtual language classroom. Language Learning \& Technology, 2, 43-61.

*Lan, Y. J., Sung, Y. T., \& Chang, K. E. (2009). Let us read together: Development and evaluation of a computer-assisted reciprocal early English reading system. Computer \& Education, 53(4), 1188-1198.

Lee, L. (2002). Enhancing learners' communication skills through synchronous electronic interaction and task-based instruction. Foreign Language Annuals, 35, 16-23.

Lee, L. (2005). Using web-based instruction to promote active learning: Learner's perspectives. CALICO Journal, 23(1), 139-156.

Lee, M. L. (2005). The effects of English songs in multimedia-based system on motivation and achievement of elementary students (Unpublished master's thesis). National Pintung University of Education, Pingtung, Taiwan.

*Li, W. L. (2009). The effects of integrating Blogging into peer feedback revision on English writing performance and attitude of vocational high school students in Taiwan (Unpublished master's thesis). National Taiwan Normal University, Taipei.

Liao, Y. K. (2007). Effects of computer-assisted instruction on students' achievement in Taiwan: A metaanalysis. Computers \& Education, 48, 216-233.

Lin, C. T. (2007). The effectiveness of web-based lessons on English classes: A case study of the multilanguage learning website by Tamkang University (Unpublished master's thesis). Tamkang University, Taipei, Taiwan. 
*Lin, M. L. (2006). A study of integrating computer technology into a preparation program for EFL prejunior High School Students (Unpublished master's thesis). National Chung Cheng University, Chiayi, Taiwan.

*Liou, H. C., Wang, H., \& Yeh, Y. L. (1992). Can grammatical call help EFL writing instruction? CALICO, 10(1), 23-44.

*Liu, P. L., Chen, C. J., \& Chang, Y. J. (2010). Effects of a computer-assisted concept mapping learning strategy on EFL college students' English reading comprehension. Computer \& Education, 54, 436445 .

*Lu, C. H. (2008). The effects of web-based instruction on English performance and attitudes of primary school students (Unpublished master's thesis). Kaohsiung Normal University, Kaohsiung, Taiwan.

Mokhtari, K., \& Reichard, C. A. (2002). Assessing students' metacognitive awareness of reading strategies. Journal of Educational Psychology. 94(2), 249-259.

Nunan, D. (1996). Towards autonomous learning: some theoretical, empirical and practical issues. In R. Pemberton, S. L. Edward, W. W. F. Or, \& H. D. Pierson (Eds.), Taking control: Autonomy in language learning (pp. 13-26). Hong Kong: Hong Kong University Press.

Nunan, D. (1997). Designing and adapting materials to encourage learner autonomy. In P. Benson, \& P. Voller (Eds.). Autonomy and independence in language learning (pp. 192-203). Harlow: Longman.

Papert, S. (1996). The connected family: Bridging the digital generation gap. New York: Longstreet.

Paris, S. G., Cross, D. R., \& Lipson, M. Y. (1984). Informed strategies for learning: A program to improve children's reading awareness and comprehension. Journal of Educational Psychology, 76(6), 1239-1252.

*Peng, C. Y., \& Hsu, P. Y. (2006). Implementing online journal practice into EFL writing class. Chaoyang Journal of Humanities and Social Sciences, 4(2), 1-32.

Pintrich, P. R., Smith, D. A. F., Garcia, T., \& McKeachie, W. J. (1991). A manual for the use of the Motivated Strategies for Learning Questionnaire (MSLQ). Ann Arbor, Michigian: National Center for Research to Improve Teaching and Learning, School of Education, University Michigan.

Pressley, M., Goodchild, F., Fleet, J., Zajchowski, R., \& Evans, E. D. (1989). The challenges of classroom instruction. Elementary School Journal, 89, 301-342.

Pressley, M., Snyder, B. L., \& Cariglia-Bull, T. (1987). How can good strategy use be taught to children? Evaluation of six alternative approaches. In S. Cormier \& J. D. Hagman (Eds.), Transfer of learning: Contemporary research and applications, (pp. 81-120). Orlando, FL: Academic Press.

Shen, Y. M. (2003). The factors affecting the reading comprehension of English content textbooks in college. Proceedings of 2003 National Conference on English Teaching and Learning, Huwei, Taiwan, 18-33.

Sheorey, R., \& Mokhtari, K. (2001). Difference in the metacognitve awareness of reading strategies among native and nonnative readers. System, 29, 431-449.

*Shiu, J. D. (2002). The effects of internet-assisted instruction and the cognitive styles of sixth graders on English achievement and motivation for learning English (Unpublished master's thesis). National Pingtung University of Education, Pingtung, Taiwan.

Soe, K., Koki, S., \& Chang, J. (2000). Effects of computer-assisted instruction (CAI) on reading achievement: A meta-analysis. Honolulu, HI: Pacific Resources for Education and Learning (ERIC Document Reproduction Service No. ED 443079). 
* Su, H. Y. (2003). A comparative study of classroom phonics instruction and web-based phonics instruction in promoting junior high school students' spelling skills (Unpublished master's thesis). National Changhua University of Education, Changhua, Taiwan.

*Tsou, W., Wang, W., \& Li, H. Y. (2002). How computers facilitate English foreign language learners acquire English abstract words. Computer \& Education, 39, 415-428.

*Tsou, W., Wang, W., \& Tzeng, Y. (2006). Applying a multimedia website in language learning. Computer \& Education, 47, 17-28.

*Wang, H. L. (2003). The effect of using the computer-assisted instruction as remedial teaching on the junior high English underachievers (Unpublished master's thesis). National Kaohsiung Normal University, Kaohsiung, Taiwan.

*Wang, M. J. (2006). Studies of web-based metacogntive reading strategy training in English reading and perceptions of web-based learning for senior high school students in southern Taiwan (Unpublished doctoral dissertation). National Kaohsiung Normal University, Kaohsiung, Taiwan.

*Wang, M. T. (2007). The effect of integrating reciprocal teaching strategies into animation on the fifth graders' English reading comprehension and motivation (Unpublished master's thesis). National Pingtung University of Education, Pingtung, Taiwan.

Yeh, I. H. (2006). The effects of reading strategies instruction on junior high school students' reading comprehension in Taiwan. (Unpublished master's thesis). National Chengchi University, Taipei, Taiwan.

Corresponding author: Mei-Mei Chang, mmchang@mail.npust.edu.tw

Australasian Journal of Educational Technology (C) 2013.

Please cite as: Chang, M.-M., \& Lin, M.-C. (2013). Strategy-oriented web-based English instruction A meta-analysis. Australasian Journal of Educational Technology, 29(2), 203-216. 